\title{
First Principles Organize Attention to and Learning About Relevant Data: Number and the Animate-Inanimate Distinction as Examples
}

\author{
ROCHEL GELMAN \\ University of Pennsylvania
}

\begin{abstract}
Early cognitive development benefits from nonlinguistic representations of skeletal sets of domain-specific principles and complementary domain-relevant data abstraction processes. The principles outline the domain, identify relevant inputs, and structure coherently what is learned. Knowledge acquisition within the domain is a joint function of such domain-specific principles and domain-general learning mechanisms. Two examples of early learning illustrate this. Skeletal preverbal counting principles help children sort different linguistic strings into those that function as the conventional count-word as opposed to labels for objects in the child's linguistic community. Skeletal causal principles, working with complementary perceptual processes that abstract information about biological and nonbiological conditions and patterns of movement, lead to the rapid acquisition of knowledge about the animate-inanimate distinction. By 3 years of age children can say whether photographs of unfamiliar nonmammalian animals, mommals, statues, and wheeled objects portray objects capable or incapable of self-generated motion. They also generate answers to questions about the insides of animate ltems more readily than ones about the insides of inanimate liems. Although these children already are artlculate about motters relevant to a theory of action, their Ilmited knowledge of growth illustrates that early skeletal princi. ples do not rule out the need to acquire new principles, in this case ones that underlie a biological account of animacy (Carey, 1985).
\end{abstract}

Preparation of this paper and the research for it was supported by my NSF grants (BNS 85-19575 and BNS 81-04881) and the William Smith Chair in Psychology. I thank Iris Levin for her help in coding the Inside-Outside data; Mary McManus for preparing the line drawing renditions of the sample of Massey and Gelman (1988) photographs; and Betty Meck, my collaborator on the interview studies. A special note of thanks to Randy Gallistel who served as a supportive and reactive audience as I worked, often outloud, on what I wanted to say in this paper.

Correspondence and requests for reprints should be sent to Rochel Gelman, Department of Psychology, 405 Hilgard Avenue, Franz Hall, UCLA, Los Angeles, CA 90024. 


\section{INTRODUCTION: \\ THE SAME ITEMS SUPPORT DIFFERENT INTERPRETATIONS}

An environment supports more than one interpretation. Children may treat the items offered in a counting lesson in a counting-relevant way, but they may not. The same items can serve as props for naming, mouthing, banging, or even balancing. Which action occurs in a given setting is determined at least as much by a child's goals as what we or the world offer. And as activities vary, so do the properties of the items that are attended to. Balancing activities require attention to the substance, weight, and size (but not the color) of the items. In contrast, counting can proceed without concern for any of the attributes of the counted items, including whether they are substantial or imagined. Given that very young children engage in both balancing (e.g., Karmiloff-Smith \& Inhelder, 1974/1975) and counting activities (e.g., Gelman \& Gallistel, 1978; Saxe, Guberman, \& Gearhart, 1988), we have to ask: How, in the early stages of development, can children focus on those aspect of experience that are relevant to one particular domain and not another?

The thesis of this paper is that the young focus on and use relevant aspects of the environment because their behavior and their assimilation of information are guided by mechanisms that embody implicit domain-specific principles. Different sets of principles guide the generation of different plans of action as well as the assimilation and structuring of their experiences. This is illustrated by a consideration of the different ways principles of causality and counting organize attention and activity.

Brown (this issue) reports that toddlers transfer their newfound tool knowledge to objects that can be used to reach and pull (or push) another object, but not to objects that share a common color or pattern with the demonstration object. Transfer occurred with short latency, showing that the children had focused on stimulus attributes relevant to the pushing and pulling of objects, for example, the rigidity, length and/or shape-at-end of a stick, as opposed to ones that are irrelevant, for example, the color or surface pattern of a stick. Brown and I believe that her subjects did this with ease because mechanisms informed by causal principles promoted the learning of causally relevant attributes. In the present example, this means that attention was guided to those factors that determine movement. Whether the young children in Brown's studies moved target objects on their own or watched others do so, it seems that all shared the ability to focus on the causally relevant information. There is evidence that implicit principles of causality are similarly engaged when infants watch a causal event (Leslie \& Keeble, 1987).

Principles of causality can also route information relevant to a causal analysis to the appropriate "file drawers" of memory. Since these memories contain causally relevant information-for example, what contributes to an object's potential for pushing or pulling another object-transfer of what is 
learned should be easy. The general tendency of the mind to assimilate characteristics of novel inputs to structured memories sets the stage for this to happen.

When it comes to counting, questions about the rigidity, length, or weight of objects in a collection are irrelevant because nothing in the counting principles requires attention to these attributes. The counter must attend to whether all items have been tagged or not, whether counting tags in a list have been repeated, skipped, reordered, and so on, but there is no reason to attend to any characteristics of the objects counted. There is nothing about the counting principles that even requires that to-be-counted items be objects, as opposed to mental events or imaginary playmates.

Whether objects are candidates for counting or tool use cannot be determined by a consideration of the objects themselves. Principles from different domains give common physical props different meanings. If we grant young children implicit knowledge of domain-relevant principles, we explain how they are able to interpret the same objects in different ways at different times.

\section{THE NATURE OF FIRST PRINCIPLES}

When I postulate that young children's cognitive development is directed by skeletal sets of domain-specific principles, I use the notion of principle in much the same way that formalists do, to define a domain of knowledge. A given set of principles, the rules of their application, and the entities to which they apply together constitute the structured outline of the domain. Since each set of principles constitutes a different structure, we have a solution to the problem of how to characterize a domain. It can be characterized in terms of a set of interrelated principles that define entities and operations on them. Counting is a part of a number-specific domain, because the representatives of numerosity (the numerons) generated by counting are operated on by mechanisms informed by, or obedient to arithmetic principles. For counting to provide the input for arithmetic reasoning, the principles governing counting must complement the principles governing arithmetic reasoning. For example, the counting principles must be such that sets assigned the same numeron are in fact numerically equal and the set assigned a greater numeron is more numerous than a set assigned a lesser numeron. Similarly, the analysis of the causation of movements is a domain because, I will conclude, there are principles that govern reasoning about the causes of motion, and there are perceptual mechanisms informed by complementary principles, which recognize different categories of causation for the movements of things (see below).

General processes like discrimination or general purpose processing mechanisms like short-term memory do not constitute domains, any more than the process of simplifying an expression constitutes a domain of mathe- 
Scripts, at least in the form in which they are often given, do not te a domain. They are analogous to the heuristic prescriptions for problems in mathematics, which should not be confused with the atical domains themselves (algebra, geometry, theory of funcc.).

rinciples that define a domain of conceptual development need not sented within the system in some symbolic form and, a fortiori, not uistic form. Rather they can be and most likely are represented inithin the structure of the information processing mechanisms that te experience and direct action (cf. Karmiloff-Smith, in press). Marr overs many cases where he believes that the algorithms by which al system processes visual input incorporate implicitly various prinjout the structure of the world Gallistel (1990; Cheng \& Gallistel, gues that the principles of Euclidean geometry are implicit in the sms by which the rat constructs and uses a map of its environment. zample of a principle implicit in a developmental mechanism comes udsen's (1983) work on the development of the tectal circuitry for ting the angular positions of distal stimuli apprehended by different modalities in the barn owl. When the experimenter intervenes to put ping of visual locations out of register with the mapping of auditory $\mathrm{s}$, the maturing circuitry reorganizes so as to bring the mappings o register. Implicit in the mechanism that controls the development c circuitry is the principle that the spatial matrix for experience is and transcends sensory modality: An object cannot have one locahe space apprehended through the visual modality and a different in the space apprehended through the auditory modality.

night suppose that the unitariness of space is an instance in which ture of the sensory data compels a particular conclusion, without the an internal mechanism whose structure already contains an implicit nent to the principle to be assimilated. However, the developmental sm committed to the unitariness of space only operates during a $d$ ('critical') period of development. When this period is past, audiI visual space remain permanently out of register in the tectum and rd's behavior. Thus, the fact that they are in register under ordinary :ances reflects a principle about the structure of space implicit in the mental mechanism that controls the effects that experience has on se of development and learning.

$I$ it helpful to think of a skeleton as a metaphor for my notion of rciples. Were there no skeletons to dictate the shape and contents of es of pertinent knowledge, then the acquired representations would rre. Just as different skeletons are assembled according to different ss, so are different coherent bodies of knowledge. Skeletons need vident on the surface of a body; similarly the underlying axiom-like 
principles which enable the acquisition of coherent knowledge need never be accessible.

The aptness of the skeleton metaphor is less than perfect because it gives the impression that all principles are in place before the body of knowledge defined by them is acquired. This need not be; it is possible, even likely in many cases, that only some subset of principles of a domain serve this function. It is also conceivable that the initial ones are replaced or expanded over the course of learning, especially if the learner acquires new or extremely enriched theories (Carey, 1985) and has the capacity for mapping language onto principles that are not at first stateable or even symbolically represented (Gelman, Cohen, \& Hartnett, 1989; Karmiloff-Smith, 1986; Mandler, 1988).

The initial principles of a domain establish the boundary conditions for the stimuli that are candidates for feeding coherent development within that domain. They function to define the constraints on the class of relevant inputs and then serve to store, in a coherent fashion, those responded to. Structural constraints do not force learners to attend to the data; they just provide guidance as to what are, and, hence, what are not the pertinent data. Furthermore, there is no claim that initial principles constitute the ultimate set of principles or that these are known in a verbally stateable or symbolized form. What is claimed is that these principles, implicit in early behavior and early information processing, lead infants to process data in ways that are consistent with the implicit principles. In the case of number, principles implicit in preverbal counting mechanisms (Gallistel, 1990) account for infants' attention to stimuli in a number-relevant way (Cooper, 1984; Moore, Benenson, Reznick, Peters, \& Kagan, 1987'; Sophian \& Adams, 1987; Starkey, Gelman, \& Spelke, 1985; Strauss \& Curtis, 1984). A skeletal set of counting and addition principles is available to support these kinds of early selective attention and the accrual of a relevant body of knowledge. In the case of causality, perceptual mechanisms sensitive to causally diagnostic features of a motion's onset (Leslie \& Keeble, 1987), trajectory, and internal coherence (Berthental, Proffitt, Spertner, \& Thomas, 1985) enable the learner

\footnotetext{
' Moore et al. state that they did not replicate Starkey, Spelke, and Gelman (1983). Strictly speaking this is true. However, their conclusion that infants do not have number-relevant processing principles is not warranted. In point of fact, where our infants chose to look at the visual display that had a corresponding number of items to the number of drum beats they heard on a trial, infants in Moore et al.'s study chose to respond to the numerially noncorresponding array. Given that infants are able to respond to both correspondences and noncorrespondences, a simple account that holds for both studies is that infants are sensitive to numerical relations that are defined by one to one correspondence.

Additionally, infants in cross-modal studies sometimes respond on the basis of sameness and sometimes on the basis of difference-even when the same stimulus kinds are used in two separate studies (Spelke, 1985). Typically, the fact that infants nevertheless responded to the experimental variables is the focus of discussion; this is not taken as a reason to conclude a failure to replicate.
} 
to recognize the causal domain relevant to the analysis of an object's behavior and thereby support the early learning of the details of surface appearance and form that frequently distinguish between animate and nonanimate things (Mandler, Bauer, \& McDonough, 1989; Smith, 1989).

As a function of everyday experiences and instruction, both the body of knowledge and the skeleton that gives it coherence will develop together. Eventually, the child will come to understand counting (and other principles of arithmetic) at many levels, enough so that even the claim that he or she re-presents number and other mathematical concepts in the stands-for, symbolic sense is correct. So will he or she come to build theories of the actions and movements of objects. Successive layers of representations will feed off ones already available or acquired.

\section{TWO EXAMPLES}

\section{Counting Principles Facilitate Counting-Relevant Interpretations of Language Strings}

Counting principles imply that one can count any collection, no matter what the characteristics of the items. As long as a different tag is used for each item, it does not matter whether the items are the same or different, substantial or imaginary, red or blue, big or little, and so forth. Principledetermined use conditions like these provide clues as to whether novel language items are count words or not. To illustrate, consider the beginning language learner who sees someone point to a set of three cups and say "one, two, three" on one occasion and "cup, cup, cup," on another occasion.

As adults, we already know that on the first occasion the items served as environmental props for counting, and on the second for labeling. That is, we know when we count we must use different tags, for example, the count words, for each item in a set, whether the items in the set are alike or different. In contrast, we also know when we name objects we must use the same word for all items in a set that are the same kind, and a different basic-level term whenever the items are different. Assume for the moment that the novice language learner does not share our knowledge of the different constraints for the different uses of word strings uttered in the context of objects. It is then easy to envision confluences of inputs that would confuse the novice regarding the different roles played by labels and count words. In the absence of any knowledge of word-use constraints, young children should either mix up count words and labels or think that they are free to label the same basic items with different labels or different basic items with the same label! Yet they do not behave as if these are options. Why not? A straightforward answer is that beginning language users, like us, follow principles that constrain the interpretation of a string of words and gestures linking them. 
Markman (this issue) and Shipley and Spelke (1988) each assume that young children are biased to think that words used in the context of a novel object refer to the object as a whole and that once an object has been named, that name applies to all exemplars from the category to which it belongs. The idea is that once a child learns that one rose is a "rose," she assumes that other exemplars of a rose are also "roses." Markman also assumes that young children have the working assumption that each kind of object has a different name (her mutual exclusivity principle). Young children's ability to sort out when novel strings are meant to be labels as opposed to entries in a count list is explained if we accept that they have implicit knowledge of both the one-label-for-classes-of-like-objects language-use rule and counting principles.

Counting requires the application of unique tags for each item in a collection, even if each of those items is of the same kind. It also requires the application of a stably ordered list of tags across count trials, even if this means assigning a different tag to like objects in different sets. Therefore, the constraints for labels as opposed to count words generate different use rules. Should children have the skeletal principles for counting and labelling, they are in a position to make good guesses as to whether they have encountered examples of language strings that are consistent with the characteristics of count words as opposed to labels.

Note the use of the phrase "good guess" in the foregoing. Adherences to the principles does not guarantee error-free, one-trial learning. Principles help the child sort the environment. But it is one task to identify the relevant string of count words and quite another to commit the list to memory, let alone to learn the base rules for generating an indefinitely large set of tags or develop a full mathematical understanding of these (e.g., Fuson, 1988; Gelman \& Greeno, 1989).

\section{Causal Principles Support Causally-Relevant Interpretations}

Early Learning of the Predictive Validity of a Complex of Cues. Findings by Massey and Gelman (1988) illustrate the hypothesis that skeletal principles about kinds of causal mechanisms direct young children's attention to one causally relevant aspect of novel items; whether they have a capacity for self-generated movement or not. The study demonstrates that children at an early age have already learned to use the complex surface characteristics that tend to distinguish between objects that do and do not have a capacity for self-generated motion. Three- and 4-year-old children were shown color photographs of a series of unfamiliar items and asked whether each of the depicted items could move itself up and down a hill or not. (Figure 1 presents black and white drawings of some of the photographed objects.) The photographed objects items were presumed to be novel because none of a separate group of 3- and 4-year-old children could name or identify them; 

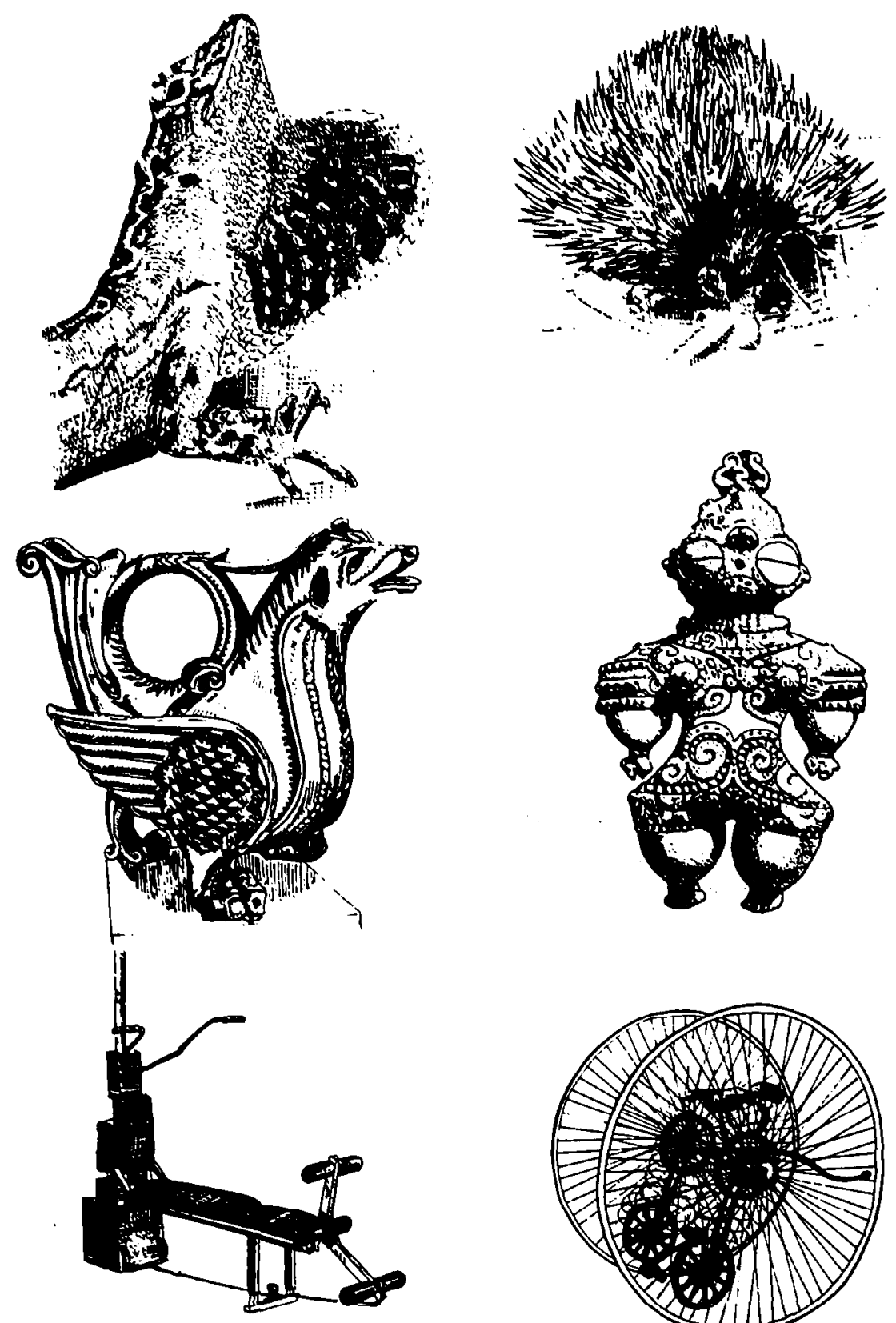

Figure 1. Line drawing renditions of some of the photographed objects used in Massey and Gelman (1988). The samples shown here, starting in the fop row and going left to right, are: a displaying lizard, on echidna, a vessel made to look like a mythical creature, an insecteped figurine, an exercise device, and an old-fashioned two-wheeled bicycle. Note that line drawings were not used in the studied reviewed in this paper. Mary McManus was the artist who drew the freehand line renditions of the actual stimuli. 
neither could most of a sample of undergraduate students in the Psychology Department at the University of Pennsylvania.

The photographs included four different exemplars from each of five categories:

1. mammals

2. non-mammalian animals

3. rigid, complex objects

4. wheeled objects

5. statues that had familiar animal-like forms and parts

From some theoretical perspectives this is a challenging task to try with such young children. We presented unfamiliar items and we asked our 3- and 4-year-old subjects to answer questions about the way these statically portrayed, unknown things could move. Our questions required that they consider issues of mechanism, an ability the Piagetian position tells us depends on the emergence of at least Concrete Operations, starting at about 6 years of age. However, there is a growing body of evidence that infants and preschool children distinguish between examples of animate and inanimate objects, either as they appear in the world or are represented by words, drawings, or three-dimensional replicas (e.g., Bullock, 1985; Gelman, Spelke, \& Meck, 1983; Golinkoff \& Harding, 1980; Keil, 1979, 1987; Mandler et al., 1989; Richards \& Siegler, 1986; Smith, 1989). Infants and preschoolers are also sensitive to the different kinds of mechanisms involved in initiating and governing the motions of animate and inanimate objects. (Baillargeon, 1986; Bullock, Gelman \& Baillargeon, 1982; Leslie \& Keeble, 1987; PoulinDubois \& Schulz, 1986).

The young children in the Massey and Gelman study reliably answered that the animals, both mammals and nonmammals, could go up and down the hill by themselves. They denied the statues this ability, despite the fact that these items looked more like the mammals than did the nonmammalian animals. Analyses of the children's individual patterns of responses showed that 17 of the 20 children used one of two variants of a causal rule of motion. For 12 of these 17 children their pattern of answers was best described by the rule that all animals can move themselves and that ail of the inanimate objects required an external agent or source in order to move. Another five children used a "choosy" variant of this rule: They sometimes denied that an animate object could go up and down a hill by itself because they thought there was a mismatch between the capacity of the depicted animal and the task it was to perform. For example, they might say that the animal in question was too little and/or the hill too big. Since they said that very same animal could do other less strenuous things by itself, they clearly were using an animate-inanimate rule but were concerned about the particular details of context. Children who did this tended to be in the younger group. 
The task elicited a great deal of talk, rich in evidence that children were concerned both about causal conditions and whether the items were animate or not. All of the inanimate object types elicited talk about the absence of agents or parts that would be needed for self-generated motion. Although the children talked about the movement-enabling parts of animate objects, sometimes even claiming they could see limbs when none were visible, they did not talk about agents when considering this class of objects. Talk about agents was restricted to the inanimate objects. This pattern of comments is consistent with our view that the Massey and Gelman study tapped into a domain concerned with the causal analysis of motion, leading children to focus on aspects of objects in the still photographs pertinent to judgments about the causes of movement of two fundamentally distinct classes of motion, animate and inanimate. Samples of what the children said buttress this conclusion. The object in question is listed before the excerpt of talk about it.

M.B. (3 yrs 7 mos)

Insect-Eye Figurine

DOWN BY SELF? No. WHY NOT? Because it's metal and doesn't have any shoes or feet.

ARE THOSE FEET? (E POINTS TO THE FEET.) No.

Rigid Complex Object

DOWN BY SELF? No. WHY NOT? It doesn't have any feet or wheels.

Echidna

DOWN BY SELF? Yeah. WHY? It has feet and no shoes.

CAN YOU POINT TO THE FEET? I can't see them.

Double Wheeled Object

UP THE HILL? It needs a push and then it goes.

L.B (3 yrs 2 mos)

Echidna

It's eating dinner.

DOWN BY SELF? Yeah. HOW COME? Cuz it has legs. ..... Not glass.

D.B. (4 yTs $1 \mathrm{mo}$ )

Praying Mantis

UP BY SELF? Yeah. HOW COME? Cause it has legs and it's real.

Home Gym

No. Because someone has to ride it.

Fantastic Bird Vessel

No. Because it's not real. ......Metal. And it has funny feet.

L.B. (3 yrs 2 mos)

Statue of a Chow Puppy

UP BY SELF? Un-uh. WHY? Because you have to throw it down and bring it up.

Tarantula (no background shown)

Yes. ... It has legs to walk and go up trees. 
Converging Evidence: The Cross-Over Design. Is it not enough to say simply that the children's attention was governed by what was salient about the objects shown? If so, then no matter what we ask children or adults to think about when looking at the same pictures, they should focus on the same aspects of these pictures. In one test of the pure saliency hypothesis Massey (1988) asked adults to pair target test items with ones that were most similar to it. Under these conditions subjects treated the statues more like the mammals than anything else-exactly what the children in the Massey and Gelman study did not do. This is our first clue that people do not focus on causally relevant information simply because such information is "salient."

Our conclusion that the same pictures lead to different response patterns depending on the questions posed, gains support from Massey's (1988) triad study with 3- and 4-year-old children. These young children reliably shifted their choices as a function of whether they were asked to judge which items looked most alike or whether they were supposed to select the items in a triad that could go up a hill on their own. We can conclude that our up-hill and down-hill questions led the children to focus on causally relevant aspects of the items while questions about overall likeness led to a focus on form per se.

Since the same children shifted their answers about the same stimuli as a function of the kind of response they were asked to give, we are in a better position to argue that these differential response patterns were governed by the application of two different representational systems. These data resemble the kind of data that lead students of animal learning to conclude that some learning is guided by internal constraints on how a given stimulus is treated. For example, when a compound cue of light and taste is paired with shock, avoidance in rats is conditioned to light but not taste. When the same compound stimulus leads to poisoning, it is taste and not light that controls avoidance behaviors (Garcia \& Koelling, 1966). Such cross-over effects serve those who argue that there are biological factors that lead organisms to find the stimuli that are relevant for a given kind of learning (see Rozin \& Schull, 1988, for a review). The studies summarized in Brown's paper in this volume also make use of this design. The cross-over design is little used in cognitive development. This is unfortunate since it offers an important research tool for assessing the view that there are domain-specific structural guidelines.

\section{Domain-Specific Principles Work in Conjunction with a Domain-General Mechanism}

How do children so young extract from still photographs the information relevant to the causes of motion for the portrayed novel items? They certainly are not born knowing what a praying mantis, or an echidna, or a wheeled artifact would look like. Nor does it seem likely that they are born with a 
detailed specification of the many surface features and details of form that tend to distinguish animate from inanimate objects. I do not think there is one or even a few features that uniquely signal animacy. Whatever the subtle characteristics that signal animacy, children learn them rapidly and at an early age. By three they have learned to recognize enough surface indices of animacy to identify unfamiliar objects like a tarantula close up and face on, a praying mantis, and an echidna, as objects that are capable of moving themselves. They already can use static surface characteristics to distinguish, with high levels of accuracy, the animals from the nonanimals-even when the animals are very unusual and bear less of a superficial resemblance to each other than they do to some of the statues.

My account of how children rapidly learn relevant information about the animate-inanimate distinction assumes the working of both domain-specific principles and domain-general learning mechanisms.

Learning the predictive validity of cues in a domain is a general process. There is a pervasive tendency for animals and people to learn about cues that have predictive validity for a given outcome, concept or setting (Brunswick, 1952; Rescorla \& Wagner, 1972). We know that red is more likely to predict tomato than is yellow; that clucking is more likely to predict a chicken than is cooing, and so on. However, to say a cue has predictive validity is not to say that it is defining. Red does not guarantee tomatoeness and clucking does not guarantee chickeness. What then does determine membership in a category? Why do some cues have high predictive validity for a category?

I propose that implicit domain-defining principles specify the core of many of the concepts and categories with which young children learn to sort the world. Domain-specific principles function to direct attention to the objects, events, or attributes that are relevant exemplars. The exemplars in turn feed general processing abilities, including the ability to extract from stored information the predictive validity of the characteristics of the items assimilated to a domain. What follows develops the case that analyzing mechanisms obedient to implicit principles that distinguish animate causality from inanimate causality focus attention on the causes of observed movements and form the conceptual core around which early learning about the animate-inanimate distinction takes place.

I propose that the acquisition of knowledge about cues that tend to distinguish between animate and inanimate objects proceeds rapidly because of processing mechanisms informed by causal principles that correspond to a deep and fundamental distinction in the world. These mechanisms make the underlying distinction between animate and inanimate objects salient and thereby favor attention to and coherent storage of relevant information abuut the distinction.

Inanimate objects cannot cause themselves to move or change; only animate objects have this ability. The cause of inanimate motion is an external 
force, and there is always a transfer of energy from one object to another or a conversion of potential energy to kinetic energy. The caluse of animate motions comes from the internally controlled and channeled release of internally stored chemical energy. Even very basic animate motions, for example, locomotion, have to a preeminent degree, a quality of purposiveness or function because they are governed by control mechanisms that constantly restore certain functional patterns in the face of perturbations and that adapt the motion to circumstances that change in unforeseeable ways (Gallistel, 1980). Animates act in ways that take into account their environments. This functionally adapted and readapted quality of animate motion is intimately tied to the fact that motion serves a function in animate beings -beings who evolve via natural selection and therefore are subject to functional constraints on their structure. It is hard to build a case that motion serves an adaptive function for inanimate objects. They are not the products of an evolutionary process that selects on the basis of successful function, which is why adaptiveness is not part of the discourse domain of physics. One does not justify Newton's third law on the grounds that it is adaptive; whereas, one does justify the oxygen uptake and release properties of hemoglobin on adaptive grounds.

Such considerations lead me to the position that our ability to develop concepts about animate and inanimate objects is guided by principled concerns for whether objects move on their own or not. I will call the principle of causal mechanism that governs attention to those natural objects that move on their own, the innards principle; I will call the causal principle that draws attention to objects that do not move on their own the external-agent principle.

Processing mechanisms that are constrained by the innards principle process events as if certain natural objects have something on the inside that governs their movement and change. The principle is neutral with respect to the nature of what a child or anyone may think it is that is on the inside and why it matters. These are things we surely learn; they vary across periods in history and cultures. Processing mechanisms that embody the external-agent principle process events as if an external agent is required for certain target objects to accelerate and move as whole in a given way. But the principle does not guarantee we will learn a particular account of physical causality; it does not favor the Aristotelean, Newtonian, quantum mechanical or any other stateable theory of physics.

Causal principles operate on, and therefore render salient, information that pertains to the fact that animate and inanimate kinds start, continue to, and stop moving in different ways. Children can develop quickly a coherent data base or body of knowledge about the animate-inanimate distinction because it is rooted in an available structure that defines relevant inputs and assimilates cases of these to a nascent skeletal structure. This structured 


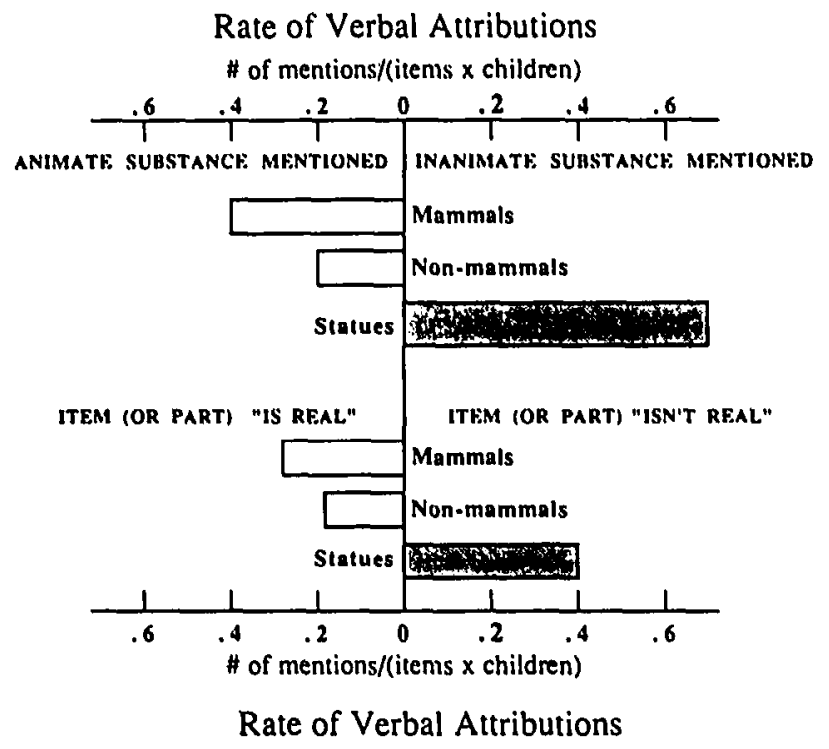

Figure 2. Children's rate of mentlon of general and specific actions while looking at mammals, nommammals, and statues in Massey and Golman (1988).

data base then serves as the source of their knowledge that some characteristics of the different items have predictive validity for the animate-inanimate distinction.

We are far from characterizing the information used to distinguish between animate and inanimate classes of objects. There are no accounts of the information for animacy that is present in photographs. We do know that by 12-months infants are sensitive to information that distinguishes between realistic three-dimensional replicas of animals and nonanimals. Smith (1989) cut up three-dimensional replicas of animals (only mammals) and vehicles, removed pieces that had eyes, faces, and wheels, then put randomly selected within-category pieces to make "animal" and "nonanimal" displays. When infants were shown these in a habituation study, they reliably discriminated between the class of 'animal' and 'non-animal' sets. Their interest in looking at a sequence of different exemplars from one class habituated; only when an item from the other was presented did they start looking again. By three or four years of age what was once but skeletal knowledge is well elaborated. Not only are children of this age able to look at a photograph and tell us that the animals portrayed have the ability to move themselves, they can say what actions are possible, and whether the object is real or made of the right material kind. Inspection of the Massey and Gelman protocols provides one source of data for this conclusion.

As noted, our stimuli elicited a lot of talk about an object's potential for movement. Figure 2 summarizes these tendencies on the part of the 3- and 
4-year-olds in Massey and Gelman. References to going, moving, or walking were classified as general. Walking is included here because the children seemed to treat it as a canonical act for going up and down hills. Occasionally denials of an animal's ability to move itself were justified on the grounds that the particular animal could not walk. Mention of all other actions were coded as specific. Examples of these occur in the protocols presented below. The figure reflects a result that surprised us. Children would claim that they could see still animates walking, jumping, and so forth. They also took the trouble to point out that the statues were not walking, moving, and so on. Although the latter was true, it was odd to hear talk about something that was not true about what they were looking at; there were so many other things they could have said about what was shown in the picture. Similarly, the claim that the animals were moving went against the fact that they were photographed in a still position.

A.C. (3 yrs 4 mos)

Echidna

---It can move very slowly. HOW CAN YOU TELL

It has these little legs. Where's the legs? Underneath?

L.B. (3 yrs 2 mos)

Marmoset

It has to carry itself up.---His mommy has to carry him up.

Tarantula

It has legs to walk and go up trees.

(There is no background in the photo.)

Tarsier (on a pole)

He's gonna get a banana..... It's dark so he can't see. And he will be scared.....

He wants to go to bed.

Echidna

It's eating dinner.

D.B. (4 yrs $1 \mathrm{mo}$ )

Praying Mantis (On a branch)

UP BY SELF Yeah. HOW COME? Cause it has legs and it's real. WHAT MAKES SOMETHING REAL? It goes brrrrrr. And then it could break the swing.

Notice that D.B. also told us that the praying mantis was real. As shown in Figure 3, she was not the only child who did. The same figure shows that children's tendency to say something was a real or not-real (fake, pretend) animal went along with a related tendency to talk about its material substance, especially if the photograph was of a statue. Terms or phrases used in the presence of statues included: wood, glass, plastic, metal, shell, clay, tin, chocolate, stone, ice, pottery, glued, cracked, not furry, rough, decorated, names for colors, shiny, smooth, and not-smooth. Terms used with animate objects included: fur, hair, beard, skin, blood, bones, brown-stuff, not- 
Incidence of Mention of Animate Actions

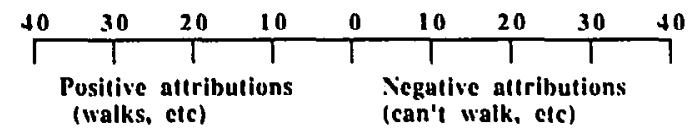

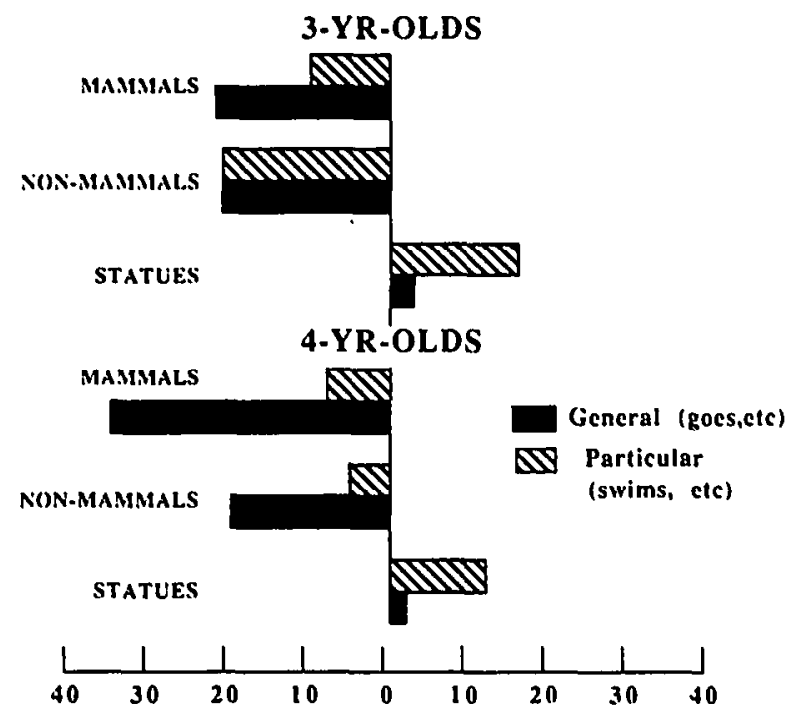

Figure 3. Children's tendencles to mention the substances or attributes of substances of mammols, nonmammals, and statues (top half of figure); and to identify os "real" or not ("not-real," "fake," or "pretend,") (bottom half of figure) in the Massey and Gelman (1988) experiment.

glass, not-metal, soft, not-breakable, and color descriptions of body parts (e.g., red mouth). Inspection of this list suggests one class of cues children gleaned from the photographs-texture, the uniformity of the surface, as well as the visual appearance of biological and nonbiological materials. ${ }^{2}$

\section{Further Evidence for the Innards and External-Agent Principles}

Insides and Outsides. Above, I argue that perceptual cues that have predictive validity for animacy need not be defining criteria. Studies that ask young children about the insides of objects help make this point because

\footnotetext{
2 Landau, Smith, and Jones (1988) report that 2- and 3-year-olds classify on the basis of shape when left to their own devices but use material kind when there are 'eyes' on the objects. The children's attention to the texture differences shown in the photographs provide evidence for the Landau et al. interpretation of the switch, that is, that eyes set children to attend to animate-relevant information, in this case material kind. So does Table 1A. In addition to the noted tendency to talk about the surface material and action enabling parts that are on the outsides of animates, our subjects repeatedly mentioned things found on or near the face-including eyes-when they talked about the outsides of animates in the absence of pictures.
} 
these questions cannot be answered solely on the basis of the data given by an object's surface. Correct answers depend on knowledge or the ability to make an educated guess using general inference rules. What kind of rules might these be?

If the innards principle is operative, a child should assume that the insides for all things that look like animate exemplars and move on their own, "in that characteristic way," contain something that causes their self-generated motion. Therefore, if they already know, or think they know an answer for any animate object, they should be inclined to say that other animates share the same thing(s) on their insides. Answers to "what is on the inside" questions, even if posed for such diverse objects as an elephant, mouse, and person should show a considerable degree of overlap. That these things look so different on the outside should not matter.

In contrast, there is no a priori reason to think the insides of inanimate objects are common across object kinds. In fact, there is really no reason why children should be especially concerned about the insides of such objects. Then, how could they answer questions about the insides of inanimate objects? As compared to when they are questioned about animate items, they might more often provide an answer for questions about "outsides" but say they do not know in response to "insides" questions. They might even say there is nothing on the inside on the assumption (erroneous or not) that there is nothing that matters. Finally, they might use their knowledge about the surface of the object and render the guess that the same thing is on the inside as is on the outside, that is, they might use a surface-appearance generalization rule.

To summarize, if the innards and external-agent principles are operative, two different kinds of generalization rules should govern answers about insides of animate and inanimate objects. In the animate case, the rule should be that the insides of different objects have much in common. Whatever is on the inside, it accomplishes the same function for all animates, making the object self-moveable. In the inanimate case, the rule should be that there either is no inside or the inside is like the outside. Note that it is only in the latter case where sensory information might figure in the solution to the task. If we are right about these different predictions, we would have clear evidence that the conditions under which sensory-based information is relevant is as much determined by the assumptions the child brings to a setting as are the conditions under which principle-based information is relevant.

The pertinent data come from an interview study that Betty Meck and I conducted. ${ }^{3}$ We asked 3-, 4-, and 5-year-old children ( $N=10 /$ age group) simply to think about animate and inanimate objects. No pictures or line drawings were presented. The animate items were person, elephant, cat,

\footnotetext{
${ }^{3}$ Hence, for purposes of expositional clarity, this study is referred to as the first Gelman and Meck interview study.
} 
mouse, and bird; the inanimate items were rock, ball, doll, and puppet. (This interview followed by a week another interview regarding the capacity of these same objects to move and grow.) For each item children were asked what they thought was on its outside and inside, and why. The decision to ask about both the inside and outside of an object came after a study with just the "inside" question that failed to elicit much talk.

Tables $1 \mathrm{~A}$ and $1 \mathrm{~B}$ list all of the kinds of answers 4- and 5-year olds gave to the inside-outside questions. Three-year-olds generally did not talk; those who did gave answers like those listed. The patterns of answers given to "inside" questions by 5-, 4, and 3-year-olds are shown in Figures 4, 5, and 6, respectively. Answers for animate items appear in the upper half of each figure and those for inanimates in the lower halves. Figure 4 shows that 5-year-old children volunteered that all of the animates have blood and bones inside; some children also knew that humans have organs on the inside as well. Notice that the children talked some about food being on the insides of animates and did so about as frequently as they talked about babies being on the inside of these objects, but this is basically a tale about blood, bones, and organs on the inside of animates.

The inside-animates pattern of blood, bones, and organs is considerably different from that obtained from the insides questions about puppets and dolls. The bars pointed to the left reflect the fact that "insides" talk about dolls and puppets was about material, (see Table 1), nothing, or some known physical mechanism (e.g., batteries, strings, etc.).

There were two notable differences between the 4-year-old and 5-year-old Inside answers: A comparison of Figures 4 and 5 reveals that the younger group talked more about food and less about internal organs when answering for animates. Also, these younger children made almost no mention of mechanisms when answering for the inanimate items, presumably because they had not learned about the specific physical mechanisms. Otherwise, we see the same pattern in both age groups. Figure 6 shows that the youngest children said that the insides of animals consist mainly of food and bones. They talked about the insides of animates as bags of bones surrounded by, or floating in, blood and/or food. In fact, one child talked about blood running through "pipe-bones." This is a very different notion than the ones the children had for dolls and puppets.

The differences presented in Figures 4, 5, and 6 are consistent with an analysis of the 4- and 5-year-olds' verbalizations that shows that two different generalization rules were used to answer questions about the insides of animates as opposed to the insides of inanimates. We coded children's answers to both the Inside and Outside part of the pair of questions for each item. Answer pairs that mentioned different attributes or objects were scored as different, those that mentioned the same attributes or objects were scored as same. For example, "hard stuff" and "color," and "colors" and "colors" for the Inside-Outside questions for a ball were coded as different and same, 
TABLE IA

List of Answers Four- and Five-Year-Old Children Give When Asked What is on the Inside and Outside of Inanimate ltems

Inside Inanimates

Rock rock, hard, hard stuff, little rocks, mud, dirt, bugs, nothing

Ball steel, plastic, color, colors, hard stuff, cotton, air, nothing

Doll hair, material, paper, stuffing, cotton, junk, rubber, leather, stuff, batteries, pipes, tongue, arms, legs, nothing

Puppet material, steel, cotton, leather, smooth, feathers, fuzzies, fur, face, bones, no blood or back, nothing
Outside Inanimates

rock, hard stuff, strong stuff, hardness, no tummy

steel, plastic, color, colors, rubber, same as inside, tiny things, stripes, decorations, pictures, no tummy, things, only a ball

hair, material, fuzzy stuff, plastic, leather, string, clothes, skin, lips, eyes, nose, ears, face, back, head

hair, fur, feathers, material, cotton, yarn, paper, eyes, face, nose, belly, nails, body, hole, nothing

TABLE $1 B$

List of Answers Four- and Five-Year-Old Children Give When Asked What is on the Inside and Outside of Animate Items

Inside Animates Outside Animates

Person blood, bones, heart, muscle, lungs, brains, body, fat, food, skeleton. tongue, teeth, bables

Elephant blood, bones, heart, the body. gums, water, flowers, birds, peanuts (last 3 were considered food)

Cat blood, bones, heart, a skeleton like people

Mouse blood, bones, heart, white mouth, cheese, fish

Bird blood, bones, heart, skin, feathers skin, hair, eyes, mouth, chin, teeth, nose, cheeks, neck, make-up, fingers, legs, elbows, ankle, hand, bellies, belly button, socks, body, bones

skin, hair, eyes, nose, mouth, a long beak, a long nose. trunk, tail, silver. gray, blue stuff

skin, fur, feathers, soft stuff, eyes, nose, mouth, whiskers, big nails

skin, fur, gray, white, eyes, ears, nose, teeth, legs, hand, arms, ankle, tail, what everyone has

skin, feathers, eyes, nose, mouth, feet, body

respectively. Answer pairs were also scored as different if children said they did not know what was on the inside but did answer the outside question, or if children said there was nothing on the inside of an object but did describe the outside. Trials where children said they did not know or did not answer either of the question pair for an item were exceedingly rare and were not coded. 
NUMBER OF CHILOREN (OF 10) WHO GIVE EACH KIND OF ANSWER

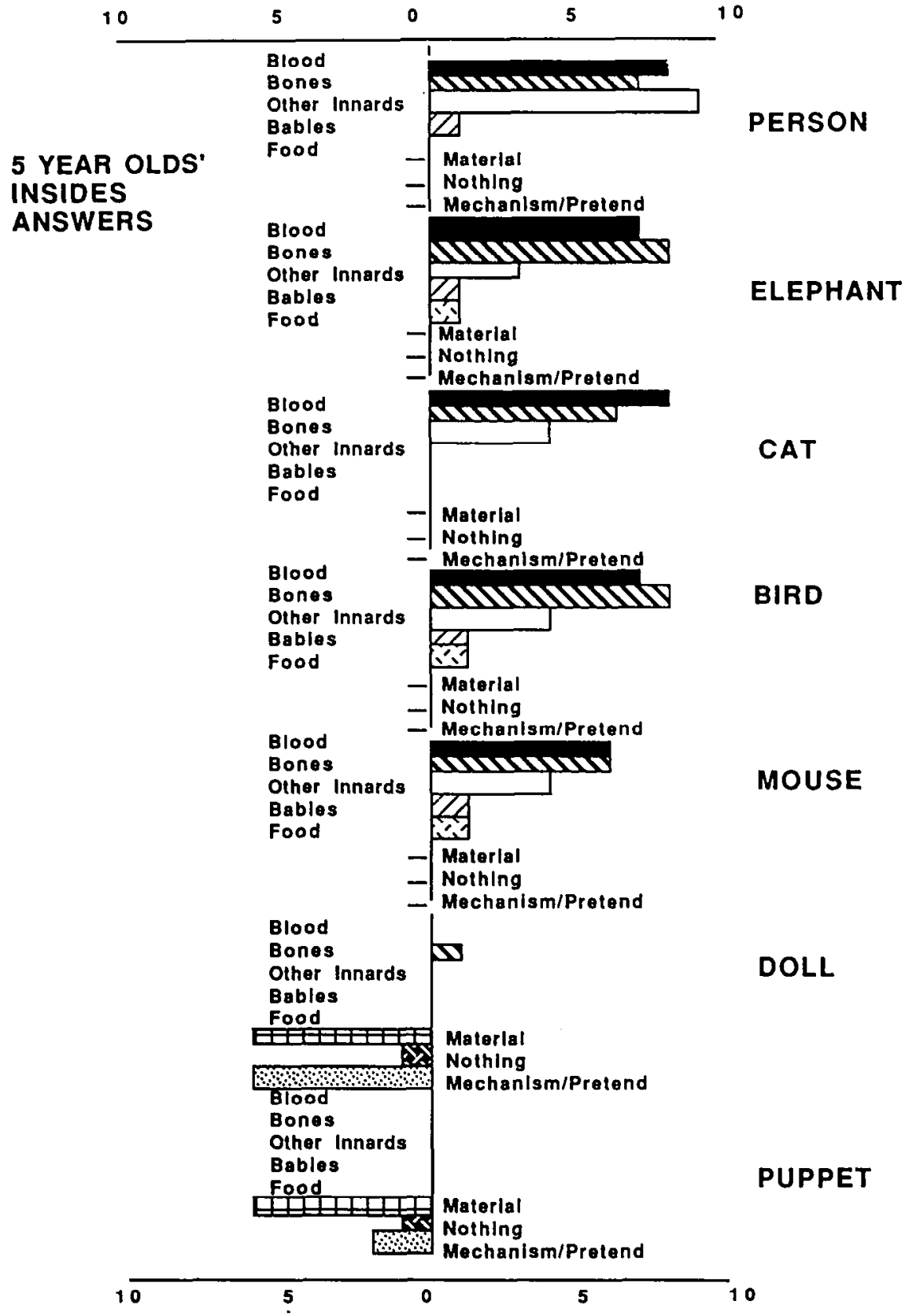

Figure 4. The number of 5-year-old children in the first Gelman and Meck interview who said test animate and inonimate items had one of the listed answers on its inside. 
NUMBER OF SS (OF 10) WHO GIVE EACH

KIND OF ANSWER

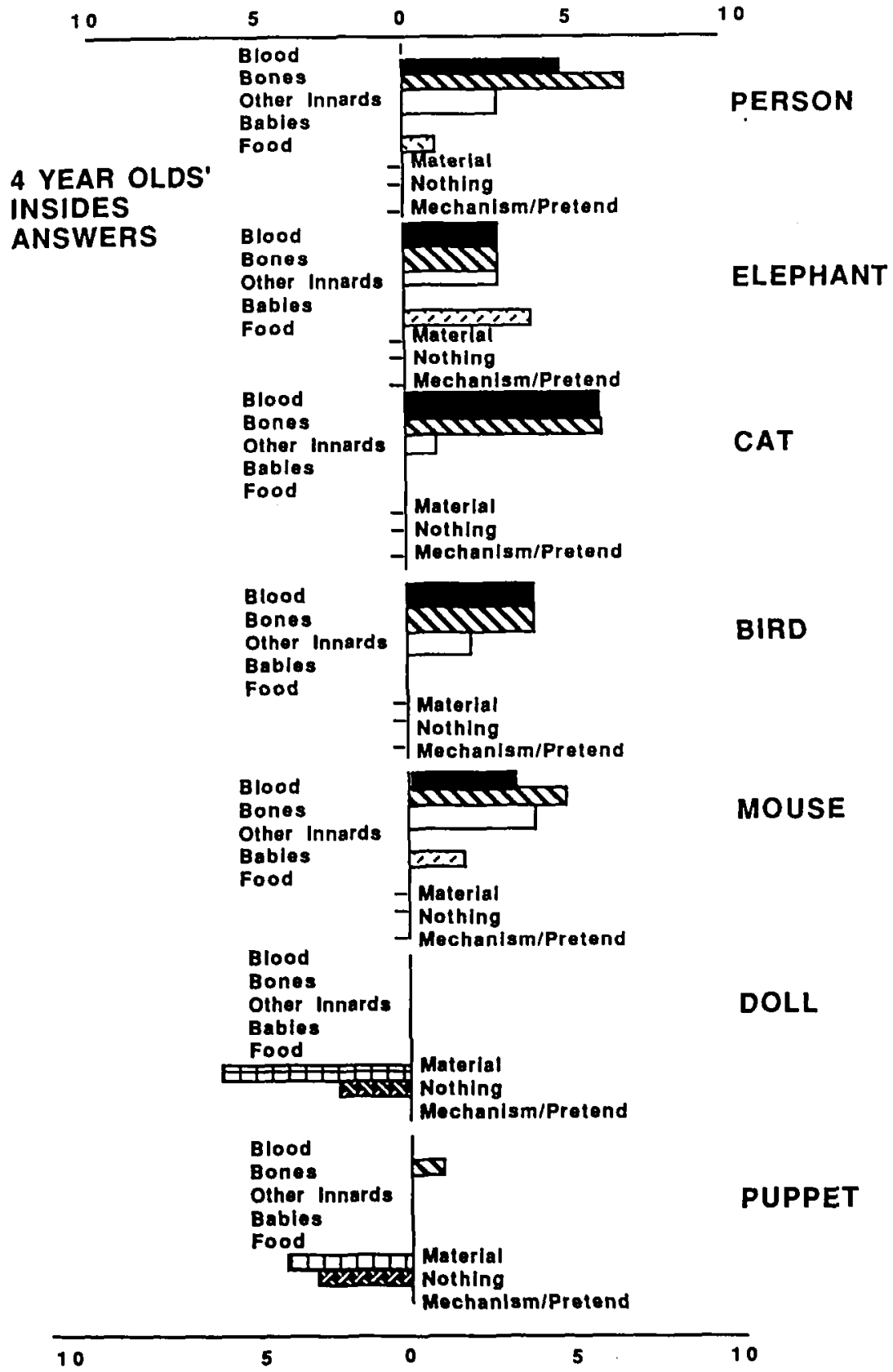

Figure 5. The number of 4-year-old children in the first Gelman and Meck interview who said test animate and inanimate items had one of the listed answers on its inside. 
NUMBER OF SS (OF 10) WHO GIVE EACH

KIND OF ANSWEA

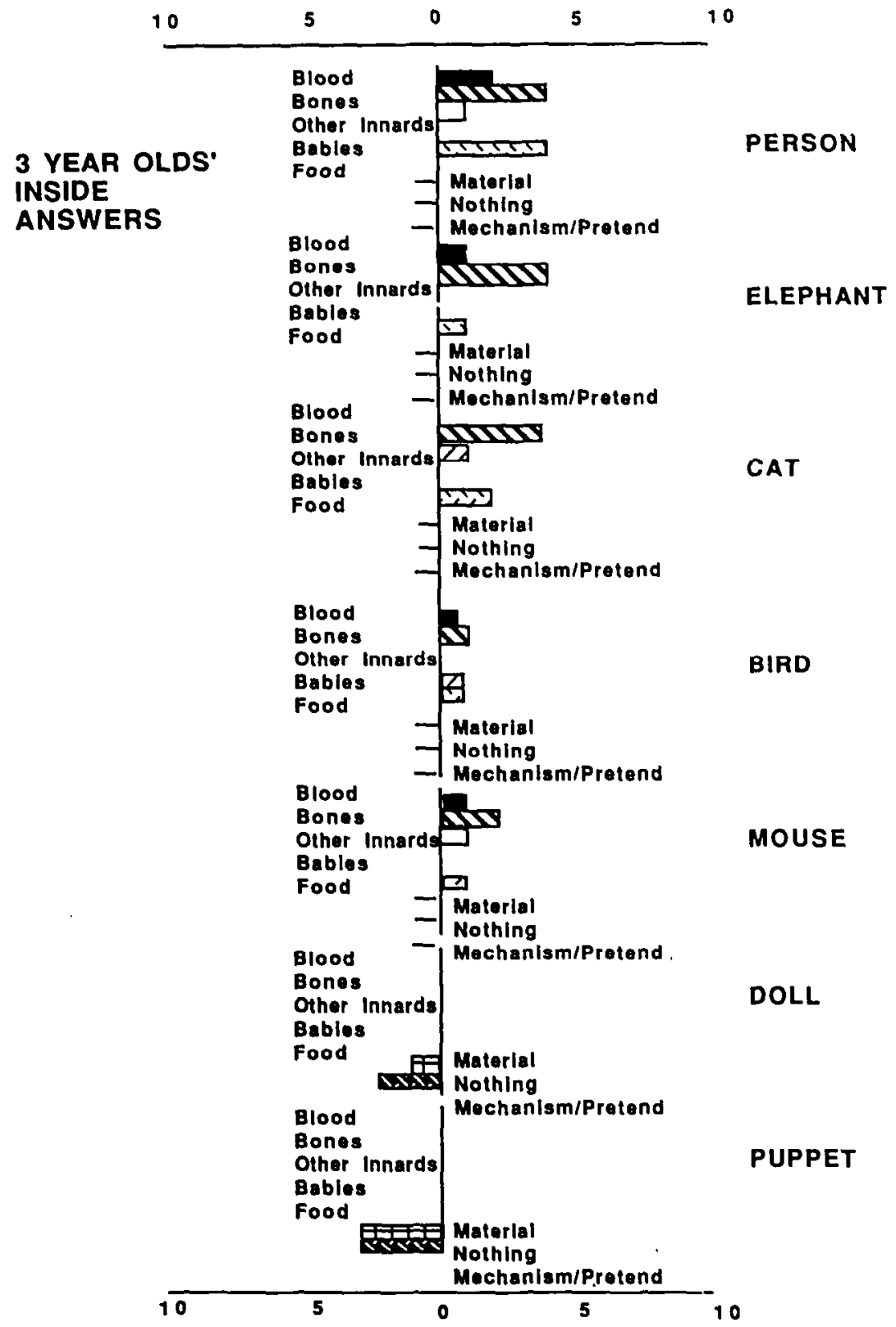

Figure 6. The number of 3-year-old children in the first Gelman and Meck interview who said test animate and inanimate liems had one of the listed answers on its inside. 
Three differences in the way children responded to the inside and outside questions are salient. First, there was almost no tendency in the 4-year-olds to use the same answer for the Inside and Outside parts of animate questions. Only $5 \%$ of all animate items were answered this way and even these cases made sense, as did the claim that skin was on both the inside and outside. No 5-year-old ever of fered the same answer for an Inside-Outside pair of questions. Children in both age groups did give the same answers for both the Inside and Outside parts of the questions about the inanimates; 32.5 and $27.5 \%$ of the items in the 4- and 5-year-old groups, respectively, were so scored. Although the other children were more likely to have more experience with balls, rocks, and dolls, they were as likely as the 4-year-olds to assign common features to the insides and outsides of inanimate objects.

Second, children responded without hesitation to the questions about the insides of animates, but hesitated when asked Inside questions about inanimates. Thus, although the children were more likely to have experience with the inanimate objects than with elephants, birds, and mice, they were more willing to provide inside answers to the latter. Answers of "don't know" or "nothing" occurred only in response to the Inside question about inanimates.

Finally, the answers to the inside questions are relatively homogeneous across the different animate kinds. In contrast, they were heterogeneous across the different inanimate types.

The tendency of young children to assimilate facts about "insides" in different ways to animates and inanimates provides evidence for the position that attention and learning in this domain is organized by domain-specific principles. In neither case are the insides of the objects usually visible or point-at-able. If anything, young children are likely to have more experience with the inanimate than the animate items used in the first Gelman and Meck interview. The tendency to use different rules of generalization can be explained if we grant the working of separate causal principles that make some data relevant and other data irrelevant for items in their respective domains.

Move Versus Grow. Carey (1985) also has studied the young child's understanding of the difference between animate and inanimate objects. Her focus is on whether children understand that all living items reproduce, grow, have a gas exchange system, and so on-whether these all possess the characteristics that modern theories of biology treat as definitional for biological kinds. My focus is on whether children understand that all animate objects can move themselves whereas no inanimates can. There is an instructive contrast between what young children have learned about the animate-inanimate distinction and what they have not learned about the alive-not-alive distinction. I hold that young children assimilate the facts they do about the animateinanimate distinction because these are consistent with the innards and ex- 
ternal-agent principles of causality. Additional support for the position would be evidence that young children do not learn and/or misinterpret facts that are not covered by these principles. One such fact is that all animates grow.

The capacity to grow subsumes a broader class of objects than does the capacity for self-initiated motion. In two further interview studies, when Betty Meck and I asked preschool children about the capacity of various living things to grow, they did not do as well as when asked about animates' capacity for growth as opposed to self-generated movement. More then $50 \%$ of 3- and 4-year-old children said "no" when asked if butterflies, worms, and fish grow, although they did think that horses and cats grow and that all of these items can move themselves. The same pattern of answers occurred in a second study where the interviewer was encouraged to follow up the yes-no question by asking the children to think about baby forms becoming adult forms. Children's comments and the pattern of answers in both studies suggests that the canonical adult size of a species determines the child's views as to whether animals of that species grow. For example, one child said "fishes don't grow because they are too little." Similar comments were obtained in yet a fourth interview study. Here, we asked subjects to consider the capacity of a list of items for movement and growth. Included in the list of items were person, bird, and plant. Not only were we told that birds are too small to grow, we also found out that people tend to grow because they have birthdays, and that trees do not move because they lack motion enabling parts like feet, legs or wheels. These are hardly biological notions about living things.

These grow versus move results help make clear that there are limits on the principles that inform the early development of the recognition and the understanding of animate-inanimate differences. Young children may be well on their way to developing a theory of action because they benefit from skeletal principles of causality that inform the processing mechanisms that respond to inputs that are relevant to animate and inanimate causality. $\mathbf{A}$ theory of action may distinguish between animate and inanimate objects. It will not however, distinguish between living and nonliving. We agree with Carey (1985): Children have to acquire a different set of principles than those that pertain to the causes of movement if they are to acquire a biological understanding of the animate-inanimate distinction.

\section{CONCLUSIONS}

\section{Implications for Theories about the Nature of Concepts}

There are implications in this work for those who ask What is a concept? I suggest that implicit information-processing principles that define skeletal categories of objects enable children to learn to recognize the diverse details 
of surface appearance and form that distinguish animate from inanimate things. In this model of knowledge acquisition, there is a clear distinction between what defines a category-in this case the categories of animate and inanimate-and what commonly determines which objects are assigned to which categories. The cues with predictive validity, the cues young children learn to recognize even in still photographs, commonly determine the category to which an object is assigned. But these cues do not define the category. Principles implicit in the mental processes of inference and action that operate on the objects in the category do.

Thus, for example, numbers are defined by the principles or axioms of arithmetic. These principles set up categories-the different numbers-but they do not say how entities in the world (say, sets of different numerosities or items with different masses) are to be numerically categorized or mapped into the system of number. Counting principles determine this mapping in the case of numerosities; weighing principles determine it in the case of mass. Similarly, in the case of causality, causal principles such as the innards and external-agent principles define the categories. But they do not specify how the members of these categories are to be recognized under everyday circumstances. The categorization of the things experienced is mediated, in part, by domain-specific perceptual mechanisms informed by complementary causal principles, and in part, by the accumulated knowledge about the predictive validity of cues, which is derived from a domain-general learning mechanism.

Part of what enables everyday categorization are mechanisms for extracting from repeated experiences the predictive power of cues. These mechanisms are in no way particular to the domain of causal analysis. In this case, however, what is extracted are the cues that predict membership in the animate category, which is defined at first by principles of causality, not by the cues that ordinarily determine categorization. On this model, concept acquisition is a joint function of domain-specific and domain-general principles.

\section{Some Initial Skeletal Principles; Not Full Blown Knowledge of the Domain}

Oft-stated criticisms of the position developed here are that knowledge in the domain is far from complete at early ages and/or that application of what is known is variable (e.g., Briars \& Siegler, 1984; Nelson, 1988; Sophian \& Huber, 1984). I opened with reasons why neither of these need apply. The body of this paper might be viewed as an existence proof, that it is possible to hold that early cognitive development benefits from innate principles without assuming that all knowledge pops out as soon as some setting condition for its use is encountered. All of the above is about how skeletal principles serve the learner who must solve the problems of relevance and coherent storage before they have learned a great deal. Domain-specific principles 
organize a domain and provide clues as to what is in it as well as a way to organize in memory what is learned-often before it is understood.

Skeletal sets of principles help the young interact with their environment because they support selective attention and coherent storage before much learning has occurred. They give the young child a "leg up" by providing the kind of mental apparatus known to support learning, structured tools for attending to and storing information in a coherent way. Learning is exceedingly hard even for adults when there are no such aids available. It could be impossible for young children were there no conceptual skeletons supporting the growth and development of body parts (principles) and the accrual of the relevant body of knowledge.

\section{REFERENCES}

Baillargeon, R. (1986). Representing the existence and the location of hidden objects: Object permanence in 6- and 8-month-old infants. Cognition, 23, 21-41.

Berthental, B.I., Proffitt, D.R., Spertner, N.B., \& Thomas, M.A. (1985). The development of infant sensitivity to biomechanical motions. Child Development, 56, 531-543.

Briars, D.J., \& Siegler, R.S. (1984). A featural analysis of preschoolers' counting knowledge. Developmental Psychology, 20, 607-618.

Brunswick, E. (1952). The conceptual framework of psychology. International Encyclopedia of Social Science, Vol. 1, Chicago: University of Chicago Press.

Bullock, M. (1985). Animism in childhood thinking: A new look at an old question. Developmental Psychology, 21, 217-225.

Bullock, M., Gelman, R., \& Baillargeon, R. (1982). The development of causal reasoning. In W.J. Friedman (Ed.), The developmental psychology of time. New York: Academic.

Carey, S. (1985). Conceptual change in childhood. Cambridge, MA: MIT Press/Bradford Books.

Cheng, K., \& Gallistel, C.R. (1984). Testing the geometric power of an animal's spatial representation. In H.L. Roitblatt, T.G. Bever, \& H.S. Terrace (Eds.), Animal cognition (pp. 409-423). Hillsdale, NJ: Erlbaum.

Cooper, R.G., Jr. (1984). Early number development: Discovering number space with addition and subtraction. In C. Sophian (Ed.), The origins of cognitive skills (pp. 157-192). Hillsdale, NJ: Erlbaum.

Fuson, K.C. (1988). Children's counting and concepts of number. New York: Springer-Verlag. Gallistel, C.R. (1980). The organization of action: A new synthesis. Hillsdale, NJ: Erlbaum. Gallistel, C.R. (1990). The organization of learning. Cambridge, MA: MIT/Bradford Press.

Garcia, J., \& Koelling, R.A. (1966). Relation of cue to consequence in avoidance learning. Psychonomic Science, 4, 123-124.

Gelman, R., Cohen, M., \& Hartnett, P. (1989). To understand number is to go beyond the belief that "numbers are what you get when you count." In Proceedings of the Eleventh Annual Meeting of the North American Chapter, International Group for Psychology of Mathematics Education. September, 1989. Rutgers University, New Brunswick, NJ.

Gelman, R., \& Gallistel, C.R. (1978). The child's understanding of number. Cambridge, MA: Harvard University Press.

Gelman, R., \& Greeno, J.G. (1989). On the nature of competence: Principles for understanding in a domain. In L.B. Resnick (Ed.), Knowing and learning: Essays in honor of Robert Glaser (pp. 125-186). Hillsdale, NJ: Erlbaum. 
Gelman, R., Spelke, E.S., \& Meck, E. (1983). What preschoolers know about animate and inanimate objects. In D. Rogers \& J.A. Sloboda (Eds.), The acquisition of symbolic skills. London: Plenum.

Golinkoff, R.M., \& Harding, C.G. (1980, March). Infants expectations of the movement potential of inanimate objects. Paper presented at the International Conference on Infant Studies, New Haven, CT.

Karmiloff-Smith, A., \& Inhelder, B. (1974/75). If you want to get ahead, get a theory. Cognition, 3, 195-212.

Karmiloff-Smith, A. (1986). From meta-processes to conscious access: Evidence from children's metalinguistic and repair data. Cognition, 23, 95-147.

Keil, F.C. (1979). Semantic and conceptual development. Cambridge, MA: Harvard University Press.

Keil, F.C. (1987). Conceptual development and category structure. In U. Neisser (Ed.), Concepts and conceptual development: Ecological and intellectual factors in categorization. (pp. 175-200) New York: Cambridge University Press.

Knudsen, E. (1983). Early auditory experience aligns the auditory map of space in the optic tectum of the barn owl. Science, 222, 939-942.

Landau, B., Smith, L.B., \& Jones, S.S. (1988). The importance of shape in early lexical learning. Cognitive Development, 3, 299-321.

Leslie, A., \& Keeble, S. (1987). Do six-month-old infants perceive causality? Cognition, 25, 265-288.

Mandler, J.M. (1988). How to make a baby: On the development of an accessible representational system. Cognitive Development, 3, 113-136.

Mandler, J.M., Bauer, P.J., \& McDonough, L. (1989). Separating the sheep from the goats: Differentiating global categories. Submitted for review. University of California, San Diego, June, 1989.

Marr, D. (1982). Vision. San Francisco: W.W. Freeman.

Massey, C. (1988). Development of the animate-inanimate distinction in preschoolers. Unpublished doctoral dissertation, University of Pennsylvania, Philadelphia.

Massey, C., \& Gelman, R. (1988). Preschoolers' ability to decide whether pictured unfamiliar objects can move themselves. Developmental Psychology, 24, 307-317.

Nelson, K. (1988). Constraints on word learning? Cognitive Development, 3, 221-246.

Poulin-Dubois, D., \& Shultz, T.R. (1986). The infant's concept of agency: The distinction between animate and inanimate objects. Unpublished manuscript, Concordia University/McGill University, Montreal, Canada.

Rescorla, R., \& Wagner, A. (1972). A theory of Pavlovian conditioning: Variations in the effectiveness of reinforcement and non-reinforcement. In A.H. Black \& W.F. Prokasy, (Eds.), Classical conditioning. II. New York: Appleton-Century Crofts.

Richards, D.D., \& Siegler, R.S. (1986). Children's understanding of the attributes of life. Journal of Experimental Child Psychology. 42, 1-22.

Rozin, P., \& Schull, J. (1988). The adaptive-evolutionary point of view in experimental psychology. In R.C. Atkinson, R.J. Hernstein, G. Lindzey, \& R.D. Luce (Eds.), Handbook of experimental psychology. (pp. 503-546) New York: Wiley-Interscience.

Saxe, G.B., Guberman, S.R., \& Gearhart, M. (1988). Social processes in early development. Monographs of the Society for Research in Child Development. 52 (Serial No. 216).

Smith, L.B. (1989, April). In defense of perceptual similarity. Paper presented at the Bi-Annual Meeting of the Society for Research in Child Development, Kansas City, MO.

Sophian, C., \& Adams, N. (1987). Infants' understanding of numerical transformations. British Journal of Developmental Psychology, 5, 257-264.

Sophian, C., \& Huber, A. (1984). Early developments in children's causal judgments. Child Development, 55, 512-526. 
Shipley, E., \& Spelke, E.S. (1988, November). Ostensive definition. Unpublished manuscript. University of Pennsylvania/Cornell University.

Spelke, E.S. (1985). Preferential looking methods as tools for the study of cognition in infancy. In G. Gottlieb, \& N. Krasnegor (Eds.), Measurement of audition and vision in the first year of postnatal life. (pp. 323-363). Norwood, NJ: Ablex.

Starkey, P.D., Gelman, R., \& Spelke, E.S. (1985). Response to Davis, Albert \& Baron's Detection of number or numerousness by human infants. Science, 288, 1222-1223.

Starkey, P.D., Spelke, E.S., \& Gelman, R. (1983). Detection of intermodal correspondences by human infants. Science, 222, 179-181.

Strauss, M.S., \& Curtis, L.E. (1984). Development of numerical concepts in infancy. In C. Sophian (Ed.), The origins of cognitive skills. Hillsdale, NJ: Erlbaum. 